\title{
Plasma 17-hydroxyprogesterone/cortisol ratio is not a predictor of systemic hypotension in extremely premature infants
}

\author{
Aurélie Lacoste ${ }^{1}$, Jean-Benoît Corcuff ${ }^{2,3}$, Antoine Benard ${ }^{4}$, Sandy Leproust ${ }^{4}$, Fabienne Nacka ${ }^{5}$, \\ Olivier Brissaud ${ }^{6}$, Pascal Barat ${ }^{1,3,5 \#}$ \\ ${ }^{1}$ Département de Pédiatrie, Endocrinologie Pédiatrique, Centre Hospitalier Universitaire Bordeaux, Bordeaux, France \\ ${ }^{2}$ Département de Médecine Nucléaire, Centre Hospitalier Universitaire Bordeaux, Bordeaux, France \\ ${ }^{3}$ Nutrition et Neurobiologie Intégrée, Universitaire de Bordeaux, Bordeaux, France \\ ${ }^{4}$ Pôle de Santé Publique, Centre Hospitalier Universitaire Bordeaux, Bordeaux, France \\ ${ }^{5}$ Département de Pédiatrie, Centre d'Investigation Clinique (CIC 0005), Centre Hospitalier Universitaire de Bordeaux, Bordeaux, \\ France \\ ${ }^{6} \mathrm{CHU}$ de bordeaux, Département de Pédiatrie, Réanimation Pédiatrique, Centre Hospitalier Universitaire de Bordeaux, Bordeaux, \\ France \\ Email: " pascal.barat@chu-bordeaux.fr
}

Received 21 February 2013; revised 20 March 2013; accepted 28 March 2013

Copyright (C) 2013 Aurélie Lacoste et al. This is an open access article distributed under the Creative Commons Attribution License, which permits unrestricted use, distribution, and reproduction in any medium, provided the original work is properly cited.

\begin{abstract}
Background/aims: To determine whether the 17-hydroxyprogesterone (17-OHP)/cortisol ratio as a marker of immature11-beta hydroxylase activity can predict severe systemic hypotension in preterm neonates. Methods: Serum cortisol and 17-OHP concentrations were measured in capillary blood deposited on blotter paper on day 3 post-natal age (Day 3 ) in infants less than 32 weeks postmenstrual age (PMA). The predictive value of $17-\mathrm{OHP} /$ cortisol ratio for a first episode of systemic hypotension occurring after Day 3 (FESH) was evaluated. Results: Of 105 infants included, 14 patients $(13 \%)$ presented a FESH. Neither the 17-OHP/cortisol ratio, nor the 17-OHP or cortisol concentrations were associated with the occurrence of a FESH when adjusted for potential confounding factors. 17-OHP and cortisol were inversely associated to PMA ( $r=-0.36$ and -0.40 , respectively). Cortisol, but not 17-OHP, was associated with the type of hospitalization unit, the respiratory support and the presence of a patent ductus arteriosus. The 17-OHP/cortisol ratio was associated with the type of hospitalization unit only. Conclusions: The 17-OHP/ cortisol ratio at Day 3 did not predict the occurrence of a first episode of systemic hypotension after Day 3 in preterm neonates.
\end{abstract}

\footnotetext{
${ }^{*}$ This study has been registered at the French National Registry (Direction Générale de la Santé) with the following number: DGS 2005/0503.

${ }^{\#}$ Corresponding author.
}

Keywords: Relative Adrenal Insufficiency; Immaturity; Congenital Adrenal Hyperplasia Screening Program

\section{INTRODUCTION}

Adequate adrenal function is a major issue for patients with acute life-threatening diseases. Elevated cortisol levels in critically-ill patients, reflecting activation of the pituitary-adrenal axis, are considered to be a homeostatic adaptation. In prolonged critical illnesses such as multiorgan failure, a state of relative or functional adrenal insufficiency characterized by an inadequate production of cortisol despite an increased demand could lead to refractory hypotension and to hydrocortisone treatment [1]. In preterm infants, severe hypotension refractory to both volume expansion and inotropic agents have been related to relative adrenal insufficiency [2]. These patients respond readily to hydrocortisone, suggesting that an inadequate hypothalamic-pituitary-adrenal (HPA) response to stress may be a major cause [2-4]. In preterm infants, effective treatments are essential because severe and prolonged hypotension is associated with increased mortality and central nervous system morbidity $[5,6]$.

During the first days of life, extremely premature infants demonstrate adequate pituitary response to human corticotrophin-releasing hormone (hCRH) $[7,8]$. Nevertheless, glucocorticoid precursors such as 17-hydroxyprogesterone (17-OHP) are relatively elevated, compared to cortisol, suggesting that the inadequate HPA response to stress may be due to an immature 11-beta hydroxylase 
activity in the adrenal glands $[9,10]$. In premature infants, low serum cortisol concentrations, an indicator of the last step of glucocorticoid production, have been shown to be associated to hypotensive episodes [11] and bronchopulmonary dysplasia [12] leading to the prophylactic administration of low dose hydrocortisone [13].

In previous studies, 11-beta hydroxylase activity has been assessed in premature infants by cortisol to 17-OHP ratio after an adrenocorticotropic hormone (ACTH) test performed after day 3 of age $[9,10]$. Combining serum 17-OHP and cortisol measurements during congenital adrenal hyperplasia (CAH) screening programs on blood spots may be an easy-to-perform and efficient means to assess the 17-OHP/cortisol ratio in the blood sampling limited population of preterm infants. This may contribute towards the identification of infants at highest risk for adverse outcomes. In this study, our main objective was to evaluate the relationship between the 17-OHP/cortisol ratio measured on the 3rd day of life and the occurrence of systemic hypotension after day 3 in extremely premature infants. We also evaluated the relationship between the 17-OHP/cortisol ratio and the occurrence of bronchopulmonary dysplasia.

\section{METHODS}

\subsection{Study Design and Population}

We conducted a prospective, prognostic cohort study. All infants born prior to 32 weeks postmenstrual age (PMA) between September 2006 and September 2007 and admitted in the neonatal intensive care unit (ICU) or the neonatology unit at the tertiary-care University Children's Hospital of Bordeaux (France) were eligible if they did not present one of the following exclusion criteria: death within the first 4 days of life, glucocorticoid administration preceding blood sampling on the 3rd day of life, congenital diseases of the heart/brain/lung/liver/ kidney diagnosed after birth and adrenal disorders diagnosed after birth (congenital adrenal hyperplasia, adrenal tumor diagnosed by ultrasonography because of hypercorticisme, adrenal hemorrhage diagnosed by ultrasonography because of adrenal insufficiency). The study protocol was approved by the ethical clinical research committee of Bordeaux University Hospital.

\subsection{Follow-Up and Outcome Measures}

In the morning of the 3rd postnatal day (Day 3), capillary blood was deposited on a disk of blotter paper for the measurement of the cortisol level in addition to the usual 17-OHP measurement for neonatal screening of congenital adrenal hyperplasia (CAH).

When systemic hypotension was noted the same therapeutic regimen was applied to infants hospitalized in the neonatal intensive care and conventional neonatology units. Monitoring of blood pressure was non-invasive and hypotension was defined as a mean arterial blood pressure $\left(\mathrm{mmH}_{2} \mathrm{O}\right)$ less than gestational age in weeks. First line therapy was 1 or 2 volume expansions with 10 to $20 \mathrm{ml} / \mathrm{kg}$ of $0.9 \%$ saline. Second line therapy after echocardiographic assessment included the addition of vasopressors (dopamine: $5-20 \mu \mathrm{g} / \mathrm{kg} / \mathrm{min}$ ) or inotropic agents (dobutamine: $5-20 \mu \mathrm{g} / \mathrm{kg} / \mathrm{min}$ ). If hypotension was life-threatening, noradrenaline was administered. As described in the literature, hydrocortisone was administered in case of vasopressor-resistant hypotension [4]. A first episode of systemic hypotension (FESH) was deemed to be present whenever the second line therapy was required for the first time between Day 3 and 32 weeks +3 days of corrected PMA. Bronchopulmonary dysplasia was defined as oxygen $\left(\mathrm{O}_{2}\right)$ dependence at 36 weeks of corrected PMA.

\subsection{Laboratory Methods for Cortisol and 17-OHP Measurements}

The blotter paper was dried and stored at room temperature. Two discs were then punched for 17-OHP and cortisol assays. After elution in buffer, one disc was processed with the 17-OHP kit for radio-immunologic assay (17-OHP-Neonatal, Cis Bio International $\left.{ }^{\circledR}\right)$. This is the routine procedure for neonatal screening of $\mathrm{CAH}$ at our institution. 17-OHP detection threshold was $17 \mathrm{nmol} / \mathrm{L}$. The other disc for cortisol assay was eluted for $1 \mathrm{~h}$ and $30 \mathrm{~min}$ at room temperature in $1 \mathrm{ml}$ with ${ }^{125}$ I-labelled cortisol buffer and processed in uniplicate with the cortisol kit (Spectria CORTISOL RIA, Orion Diagnostica ${ }^{\circledR}$ ). Cortisol detection threshold was $40 \mathrm{nmol} / \mathrm{L}$ [14]. 17-OHP assay CV were $14.8 \%$ \& $15.4 \%$ (for $33.5 \& 89.7 \mathrm{nmol} / \mathrm{L}$, respectively) and cortisol assay CV were $5.2 \% \& 6.5 \%$ (for $63 \& 425 \mathrm{nmol} / \mathrm{L}$, respectively).

\subsection{Statistical Analysis}

\subsubsection{Descriptive Analysis}

Quantitative variables were described by frequency, mean, standard deviation of the mean, median and interquartile range (IQR). Qualitative variables were described by frequency and percentage.

\subsubsection{Modeling}

Logistic regression models were performed to analyze dichotomous outcomes, such as the occurrence of a FESH or the occurrence of bronchopulmonary dysplasia. Potential confounding factors associated with these outcomes in univariate analysis (conservative threshold $\mathrm{p}$-value $<0.25$ ) were then introduced in multivariate analyses. Postmenstrual age, birthweight, patent ductus arteriosus, hospitalization unit, respiratory support, mode of delivery, sex, maternal-fetal infection and Apgar 1 min were considered. Results are summarized as ad- 
justed odds ratios and corresponding $95 \%$ confidence intervals $(95 \% \mathrm{CI}) .17-\mathrm{OHP}$, cortisol and 17-OHP/cortisol ratio levels were analyzed using linear regression models, after a logarithmic transformation to respect the normality hypothesis of the linear model. Same confounding factors as in logistic regression models were tested in univariate analysis. For all analyses, hypothesis testing was 2 -sided, with p-values of $<0.05$ being considered statistically significant. All analysis was conducted with SAS 9.1 software. As this was an exploratory observational study it was decided to perform analysis on available data without any strategy to replace missing values.

\section{RESULTS}

\subsection{Characteristics of the Population}

A total of 107 patients were eligible. Two patients were excluded: one had received hydrocortisone prior to Day 3; the other died on Day 3. The characteristics of the study population are described in Table 1. One hundred and five patients were included in the analysis. Between delivery and Day 3, 7 patients experienced hypotension including $4(3.8 \%)$ requiring inotropic agents. Ten patients $(9.5 \%)$ died during follow-up ( 3 due to respiratory complications, 3 due to circulatory failure, 3 with neurological complications and 1 from necrotizing enterocolitis).

\subsection{7-OHP/Cortisol Ratio as Predictor of a First Severe Episode of Hypotension}

A FESH was observed in $14(13.0 \%)$ patients. Three patients received hydrocortisone treatment. The univariate analysis showed that the $17-\mathrm{OHP} /$ cortisol ratio was not associated with the occurrence of a FESH (Odds Ratio (OR): 1.23 ; $95 \%$ CI: $0.50-3.02 ; \mathrm{p}=0.64$ ). In the multivariate analysis (Table 2), postmenstrual age was the only factor associated with the occurrence of a FESH: the higher the gestational age, the lower the risk of systemic hypotension $\left(\mathrm{p}<10^{-3}\right)$. Median 17-OHP/cortisol ratio in patients with and without a FESH were 0.67 [range $0.11-3.19$ ] and 0.98 [0.19 - 2.14], respectively.

\subsection{7-OHP and Cortisol as Predictors of a First Severe Episode of Hypotension}

In the univariate analysis, 17-OHP level but not cortisol level significantly predicted a FESH (OR: $1.22 ; 95 \% \mathrm{CI}$ : $1.06-1.41 ; \mathrm{p}=0.01$ and OR: $1.05 ; 95 \%$ CI: $0.99-1.11$; $\mathrm{p}=0.07$, respectively). Adjusted on PMA, 1 minute Apgar score and gender, 17-OHP significantly predicted the occurrence of a FESH (OR: 1.21; 95\% CI: 1.00 - 1.46) (Table 2). In this multivariate analysis, gestational age was also associated with a FESH (OR: $0.45 ; 95 \%$ CI:
Table 1. Characteristics of the population studied.

\begin{tabular}{|c|c|c|c|}
\hline Before delivery & & & \\
\hline Antenatal corticosteroids & & & \\
\hline Number of doses, $N$ median [range] & 89 & 1 & {$[1-2]$} \\
\hline $\begin{array}{l}\text { Time between last dose and delivery } \\
\text { (days), } n / N \text { median [range] }\end{array}$ & $84 / 89$ & 1 & {$[0-27]$} \\
\hline Mode of delivery (vaginal), $n / N(\%)$ & $12 / 105$ & $(11.4)$ & \\
\hline \multicolumn{4}{|l|}{ Delivery } \\
\hline $\begin{array}{l}\text { Postmenstrual age (weeks), } \\
N \text { median [interquartile range] }\end{array}$ & 105 & 29 & {$[27-30]$} \\
\hline $\begin{array}{l}\text { Premature rupture of membranes } \\
\qquad(>24 \mathrm{~h}), n / N(\%)\end{array}$ & $18 / 102$ & $(17.6)$ & \\
\hline Sex: male, $n / N(\%)$ & $58 / 105$ & $(55.2)$ & \\
\hline $\begin{array}{l}\text { Birth weight }(\mathrm{kg}), N \text { median } \\
\quad \text { [interquartile range }]\end{array}$ & 105 & 1.1 & {$[0.9-1.4]$} \\
\hline $\begin{array}{l}\text { Apgar } 1 \text { min, } N \text { median } \\
\text { [interquartile range] }\end{array}$ & 100 & 7 & {$[3-9]$} \\
\hline \multicolumn{4}{|l|}{ Day 3} \\
\hline Foeto-maternal infection, $n / N(\%)$ & $6 / 104$ & $(5.7)$ & \\
\hline Patent ductus arteriosus, $n / N(\%)$ & $42 / 105$ & $(40.0)$ & \\
\hline $\begin{array}{c}\text { Hospitalization unit } \\
\text { (intensive care unit), } n / N(\%)\end{array}$ & $54 / 104$ & $(51.9)$ & \\
\hline \multicolumn{4}{|l|}{ Respiratory support } \\
\hline None, $n / N(\%)$ & $30 / 105$ & $(28.6)$ & \\
\hline Conventional/HFO, $n / N(\%)$ & $35 / 105$ & $(33.3)$ & \\
\hline CPAP, $n / N(\%)$ & $40 / 105$ & $(38.1)$ & \\
\hline $\begin{array}{l}\text { 17-OHP level (nmol/l), } N \text { median } \\
\text { [interquartile range }]\end{array}$ & 105 & 58 & {$[38-83]$} \\
\hline $\begin{array}{l}\text { Cortisol level (nmol/l), } N \text { median } \\
\text { [interquartile range] }\end{array}$ & 105 & 79 & {$[52-113]$} \\
\hline $\begin{array}{c}\text { 17-OHP/cortisol ratio, } N \text { median } \\
\text { [interquartile range }]\end{array}$ & 105 & 0.7 & {$[0.4-1.1]$} \\
\hline
\end{tabular}

Mean, SD for quantitative parameters; $n, \%$ for qualitative parameters, $\mathrm{N}$ indicates the total number of cases. CPAP: continuous positive airway pressure; HFO: high frequency oscillation.

$0.27-0.74)$. In the multivariate analysis of the association between cortisol and systemic hypotension, PMA was the only factor associated with the occurrence of a FESH (OR: 0.40; 95\% CI: 0.25 - 0.64). Median 17-OHP and cortisol in patients with and without a FESH were $83.7 \mathrm{nmol} / 1[32.0-174.0]$ and $56.0 \mathrm{nmol} / 1$ [13.0 - 218.0], respectively, and $91.7 \mathrm{nmol} / 1$ [47.0 - 481.0] and 78.0 $\mathrm{nmol} / 1[15.0$ - 465.0], respectively.

\subsection{7-OHP/Cortisol Ratio, Cortisol and 17-OHP as Predictors of Bronchopulmonary Dysplasia}

Fifteen $(14.0 \%)$ patients presented an $\mathrm{O}_{2}$-dependence at 
Table 2. Multivariate logistic regression model of plasma $17-$ $\mathrm{OHP} /$ cortisol ratio, 17-OHP and cortisol as predictors of a first systemic episode of hypotension.

\begin{tabular}{|c|c|c|c|}
\hline & OR & CI 95\% & p-value \\
\hline $\begin{array}{c}\text { 17-OHP/cortisol ratio } \\
\text { (for each increase of } 10 \text { points) }\end{array}$ & 1.80 & {$[0.62-5.26]$} & 0.28 \\
\hline $\operatorname{PMA}(w k)$ & 0.38 & {$[0.24-0.61]$} & $<10^{-3}$ \\
\hline $\begin{array}{c}17-\mathrm{OHP} \\
\text { (for each increase of } 10 \mathrm{nmol} / \mathrm{l})\end{array}$ & 1.21 & {$[1.00-1.46]$} & 0.04 \\
\hline PMA (wk) & 0.45 & {$[0.27-0.74]$} & 0.002 \\
\hline $\begin{array}{c}\text { Apgar } 1 \text { min } \\
\text { (for each increase of } 1 \text { ) }\end{array}$ & 0.78 & {$[0.58-1.04]$} & 0.09 \\
\hline Gender (male vs female) & 0.23 & {$[0.04-1.28]$} & 0.09 \\
\hline $\begin{array}{c}\text { Cortisol } \\
\text { (for each increase of } 10 \mathrm{nmol} / \mathrm{l})\end{array}$ & 1.02 & {$[1.01-1.09]$} & 0.48 \\
\hline PMA (wk) & 0.40 & {$[0.25-0.64]$} & $<10^{-3}$ \\
\hline
\end{tabular}

PMA: postmenstrual age.

36 weeks of corrected PMA. Univariate analysis showed no association between $\mathrm{O}_{2}$-dependence and the 17-OHP/ cortisol ratio (OR: $0.50 ; 95 \%$ CI: $0.16-1.56 ; \mathrm{p}=0.23$ ), cortisol (OR: 1.06; 95\% CI: $0.90-1.23 ; \mathrm{p}=0.48$ ) or 17-OHP (OR: 1.03; 95\% CI: $0.96-1.11 ; \mathrm{p}=0.4$ ) levels at Day 3.

Adjusted on PMA and patent ductus arteriosus, 17OHP/cortisol ratio, cortisol and 17-OHP levels at Day 3 were not associated with $\mathrm{O}_{2}$-dependence at 36 weeks of corrected PMA. In these adjusted analyses, PMA remained the only predicting factor of bronchopulmonary dysplasia (Table 3).

\subsection{Factors Influencing 17-OHP or Cortisol Levels and the 17-OHP/Cortisol Ratio}

The 17-OHP and cortisol levels, as well as the 17-OHP/ cortisol ratio are shown in Table 1. In the univariate analysis, 17-OHP and cortisol were negatively correlated with PMA and birth weight (Table 4). However, these associations were weak as the correlation coefficients regarding PMA were -0.36 for $17-\mathrm{OHP}$ and -0.40 for cortisol, and regarding birth weight, -0.28 for $17-\mathrm{OHP}$ and -0.30 for cortisol, respectively. Cortisol was also associated with the type of hospitalization unit (hospitalization in the ICU was associated to a higher cortisol level compared to a conventional neonatology ward), respiratory support (continuous positive airway pressure (CPAP) or mechanical ventilation support-versus no support-involved a higher cortisol level) and patent ductus arteriosus (higher cortisol level for infants with a patent ductus arterious) (Table 4). The 17-OHP/cortisol ratio was associated with the type of hospitalization unit only. Other potential confounding factors such as the
Table 3. Multivariate logistic regression model of plasma 17$\mathrm{OHP} /$ cortisol ratio, 17-OHP and cortisol as predictors of bronchopulmonary dysplasia.

\begin{tabular}{cccc}
\hline & OR & CI 95\% & p-value \\
\hline $\begin{array}{c}\text { 17-OHP/cortisol ratio } \\
\text { (for each increase of 10 points) }\end{array}$ & 0.69 & {$[0.20-2.32]$} & 0.55 \\
PMA (wk) & 0.66 & {$[0.40-1.08]$} & 0.09 \\
$\begin{array}{c}\text { Patent ductus arteriosus } \\
\text { 17-OHP }\end{array}$ & 11.45 & {$[1.04-125.83]$} & 0.05 \\
\hline $\begin{array}{c}\text { PMA (wk) } \\
\text { (for each increase of 10 nmol/1) }\end{array}$ & 0.97 & {$[0.81-1.16]$} & 0.76 \\
$\begin{array}{c}\text { Patent ductus arteriosus } \\
\text { Cortisol }\end{array}$ & 0.65 & {$[0.39-1.07]$} & 0.09 \\
\hline $\begin{array}{c}\text { PMA (wk) } \\
\text { (for each increase of 10 nmol/1) }\end{array}$ & 0.97 & {$[1.04-126.77]$} & 0.01 \\
\hline $\begin{array}{c}\text { Patent ductus arteriosus } \\
\text { P. } 1.07]\end{array}$ & 0.65 & {$[0.40-1.07]$} & 0.09 \\
\hline
\end{tabular}

PMA: postmenstrual age.

number of doses of antenatal corticosteroids, delivery mode, gender, Apgar score at $1 \mathrm{~min}$, episodes of hypotension before Day 3, and feto-maternal infection showed no significant association with 17-OHP, cortisol or 17-OHP/cortisol levels. In the multivariate analysis, 17-OHP and cortisol levels were associated with PMA only whereas $17-\mathrm{OHP} /$ cortisol ratio was associated with the type of hospitalization unit only, with a lower $17-\mathrm{OHP} /$ cortisol ratio in the ICU compared to the conventional neonatology units.

\section{DISCUSSION}

Utilizing the routine procedure for $\mathrm{CAH}$ screening, our study was designed to test the hypothesis that the 17$\mathrm{OHP} /$ cortisol ratio measured at 3 days of age as a marker of immature 11-beta hydroxylase activity could predict severe systemic hypotension in preterm neonates less than 32 weeks of PMA. The limit of 32 weeks of PMA was chosen because 17-OHP/cortisol ratio has been found to be lower in less than 30 weeks of gestational age (i.e. 32 weeks of PMA) neonates than in 30 to 33 weeks of gestational age (i.e. 32 to 35 weeks of PMA) neonates [10]. We found that neither 17-OHP/cortisol ratio nor serum 17-OHP or cortisol concentrations were associated with a first episode of systemic hypotension requiring second line therapy and occurring after Day 3.

Developmental immaturity of the HPA axis in preterm infants may result in insufficient cortisol production to maintain homeostasis. This state considered as relative adrenal insufficiency is characterized by an inadequate production of cortisol in relation to an increased demand during periods of severe stress, such as severe systemic 
Table 4. Potential confounding factors associated with plasma 17-OHP, cortisol or 17-OHP/cortisol ratio: univariate linear regression model.

\begin{tabular}{|c|c|c|c|c|c|c|c|}
\hline & \multirow[b]{2}{*}{$\mathrm{n}$} & \multicolumn{2}{|c|}{ 17-OHP } & \multicolumn{2}{|c|}{ Cortisol } & \multicolumn{2}{|c|}{ 17-OHP/cortisol } \\
\hline & & $\begin{array}{l}\text { Parameter } \\
\text { estimation }\end{array}$ & $\mathrm{p}$-value & $\begin{array}{l}\text { Parameter } \\
\text { estimation }\end{array}$ & p-value & $\begin{array}{l}\text { Parameter } \\
\text { estimation }\end{array}$ & p-value \\
\hline Gestational age (weeks) & 105 & -0.11 & $<10^{-3}$ & -0.13 & $<10^{-3}$ & - & - \\
\hline Birth weight $^{*}$ & 105 & -0.04 & 0.003 & -0.05 & 0.003 & - & - \\
\hline Hospitalization unit & - & - & - & & & & \\
\hline ICU vs. conventional & & & & 0.41 & 0.001 & -0.34 & 0.01 \\
\hline Respiratory support & - & - & & & & - & - \\
\hline None & & & & Reference & 0.002 & & \\
\hline CPAP vs. none & & & & 0.44 & 0.002 & & \\
\hline Mechanical ventilation vs. no support & & & & 0.48 & 0.001 & & \\
\hline Patent ductus arteriosus & - & - & - & 0.36 & 0.003 & - & - \\
\hline
\end{tabular}

Only significant associations are presented; ${ }^{*}$ for each increase of 100 grams. CPAP: continuous positive airway pressure; ICU: intensive care unit.

hypotension or pulmonary distress in premature infants. Based on a hCRH test, it has been shown that low cortisol levels were associated with the presence or the severity of systemic hypotension [2,11]. Adrenocorticotrophic hormone $(\mathrm{ACTH})$ tests performed on the 5 th postnatal day predicted the occurrence of bronchodysplasia in preterm infants [12]. However, responsiveness to the hCRH test in this population appeared to be well-adapted [2] and developmental immaturity of the HPA may be more related to inadequate adrenal gland production of cortisol and more precisely the enzymatic activity. It is well known that 17-OHP levels are inversely correlated to PMA, leading to false positive screening of CAH in preterm infants [15]. This enzymatic immaturity may involve the 11-beta hydroxylase enzyme to a greater extent than 3-beta hydroxylase, leading to high 17-OHP and 11-deoxycortisol levels, and low cortisol levels in preterm infants less than 30 weeks gestational age compared to full term infants $[9,10]$.

In the current study, we chose to test an easy-to-perform procedure during the $\mathrm{CAH}$ screening program to evaluate the 11-beta hydroxylase activity early in life in order to screen infants at risk for relative adrenal insufficiency with the perspective of a possible generalization of our approach. Our study was designed with 17-OHP/ cortisol ratio as the main measure. These analytes were measured in total capillary blood, thus comparison with assays in venous serum should take this into account [14]. We found that serum 17-OHP/cortisol concentrations ratio remained constant in the youngest infants aged less than 32 weeks of corrected PMA. We did not confirm expected low serum cortisol concentrations in the more premature infants. On the contrary, we found inverse correlations between cortisol, 17-OHP levels and PMA. One may argue that the use of only one blood sample is not appropriated for the correct evaluation of adrenal secretion. However, in neonates, a nycthemeral rhythm of adrenal secretion does not appear until approximately 3 months of age [16]. The ultradian rhythmicity is more discreet in premature infants compared to full term neonates, with a longer secretory burst half-duration and a lower maximal secretory rate of cortisol [17].

During one year of recruitment in our tertiary neonatal centre, only $13 \%$ infants have presented systemic hypotension event requiring second line therapy after Day 3 and only three of them needed hydrocortisone as treatment of refractory hypotension. These proportions could be responsible for a lack of power of our study. However, our results are in accordance to recently published data from a multicenter trial for the prevention of early adrenal insufficiency, finding that cortisol concentrations at day 5 to 7 were not predictive of adverse short-term outcomes, and particularly not predictive of an open-label hydrocortisone use [18]. In our study, we could expect that an early cortisol concentrations measured at Day 3 could be more sensitive for detecting patients with relative adrenal insufficiency. Nevertheless, cortisol concentrations were more elevated in neonates admitted in intensive care unit, with invasive respiratory support and a patent ductus arteriosus, independently of gestational age, showing an adapted stress secretion.

Then, the 17-OHP/cortisol ratio measured on postnatal Day 3 as a marker of enzymatic adrenal immaturity did not predict the occurrence of systemic hypotension in premature infants. The relatively constant $17-\mathrm{OHP} /$ cortisol ratio and the adapted-to-stress cortisol secretion 
suggest relatively matured adrenal function in most of the neonates less than 32 weeks of PMA.

\section{ACKNOWLEDGEMENTS}

The authors are indebted to Pr Michael Fayon for manuscript review; physicians and nurses of the neonatal unit and neonatal intensive care unit for their participation to the study and to Sandrine Vautra (CICpédiatrique INSERM) and Catherine Dubeau for technical support.

\section{REFERENCES}

[1] Beishuizen, A. and Thijs, L.G. (2001) Relative adrenal failure in intensive care: An identifiable problem requiring treatment? Best Practice \& Research: Clinical Endocri- nology \& Metabolism, 15, 513-531. doi:10.1053/beem.2001.0167

[2] Ng, P.C., Lam, C.W., Fok, T.F., Lee, C.H., Ma, K.C., Chan, I.H. and Wong, E. (2001) Refractory hypotension in preterm infants with adrenocortical insufficiency. Archives of Disease in Childhood. Fetal and Neonatal Edition, 84, F122-F124. doi:10.1136/fn.84.2.F122

[3] Seri, I., Tan, R. and Evans, J. (2001) Cardiovascular effects of hydrocortisone in preterm infants with pressorresistant hypotension. Pediatrics, 107, 1070-1074. doi:10.1542/peds.107.5.1070

[4] Dasgupta, S.J. and Gill, A.B. (2003) Hypotension in the very low birthweight infant: The old, the new, and the uncertain. Archives of Disease in Childhood. Fetal and Neonatal Edition, 88, F450-F454. doi:10.1136/fn.88.6.F450

[5] Watkins, A.M., West, C.R. and Cooke, R.W. (1989) Blood pressure and cerebral haemorrhage and ischaemia in very low birthweight infants. Early Human Development, 19, 103-110. doi:10.1016/0378-3782(89)90120-5

[6] Low, J.A., Froese, A.B., Galbraith, R.S., Smith, J.T., Sauerbrei, E.E. and Derrick, E.J. (1993) The association between preterm newborn hypotension and hypoxemia and outcome during the first year. Acta Paediatrica, 82, 433-437. doi:10.1111/j.1651-2227.1993.tb12717.x

[7] Hanna, C.E., Keith, L.D., Colasurdo, M.A., Buffkin, D.C., Laird, M.R., Mandel, S.H., Cook, D.M., LaFranchi, S.H. and Reynolds, J.W. (1993) Hypothalamic pituitary adrenal function in the extremely low birth weight infant. The Journal of Clinical Endocrinology \& Metabolism, 76, 384-387. doi:10.1210/jc.76.2.384

[8] Ng, P.C., Lam, C.W., Lee, C.H., Ma, K.C., Fok, T.F., Chan, I.H. and Wong, E. (2002) Reference ranges and factors affecting the human corticotropin-releasing hormone test in preterm, very low birth weight infants. The Journal of Clinical Endocrinology \& Metabolism, 87, 4621-4628. doi:10.1210/jc.2001-011620
[9] Hingre, R.V., Gross, S.J., Hingre, K.S., Mayes, D.M. and Richman, R.A. (1994) Adrenal steroidogenesis in very low birth weight preterm infants. The Journal of Clinical Endocrinology \& Metabolism, 78, 266-270. doi:10.1210/jc.78.2.266

[10] Bolt, R.J., Van Weissenbruch, M.M., Popp-Snijders, C., Sweep, F.G., Lafeber, H.N. and Delemarre-van de Waal, H.A. (2002) Maturity of the adrenal cortex in very preterm infants is related to gestational age. Pediatric Research, 52, 405-410. doi:10.1203/00006450-200209000-00017

[11] Ng, P.C., Lee, C.H., Lam, C.W., Ma, K.C., Fok, T.F., Chan, I.H. and Wong, E. (2004) Transient adrenocortical insufficiency of prematurity and systemic hypotension in very low birthweight infants. Archives of Disease in Childhood. Fetal and Neonatal Edition, 89, F119-F126. doi:10.1136/adc.2002.021972

[12] Watterberg, K.L. and Scott, S.M. (1995) Evidence of early adrenal insufficiency in babies who develop bronchopulmonary dysplasia. Pediatrics, 95, 120-125.

[13] Watterberg, K.L., Gerdes, J.S., Cole, C.H., Aucott, S.W., Thilo, E.H., Mammel, M.C., Couser, R.J., Garland, J.S., Rozycki, H.J., Leach, C.L., Backstrom, C. and Shaffer, M.L. (2004) Prophylaxis of early adrenal insufficiency to prevent bronchopulmonary dysplasia: A multicenter trial. Pediatrics, 114, 1649-1657. doi:10.1542/peds.2004-1159

[14] Nassima, B., Mimouni, S., Ourioux, C., Gatta, B. and Corcuff, J.B. (2007) Capillary blood, an alternative to saliva for the diagnosis of Cushing's syndrome? Clinica Chimica Acta, 383, 182-183. doi:10.1016/j.cca.2007.04.025

[15] Nordenstrom, A., Wedell, A., Hagenfeldt, L., Marcus, C. and Larsson, A. (2001) Neonatal screening for congenital adrenal hyperplasia: 17-hydroxyprogesterone levels and CYP21 genotypes in preterm infants. Pediatrics, 108, E68. doi:10.1542/peds.108.4.e68

[16] Vermes, I., Dohanics, J., Toth, G. and Pongracz, J. (1980) Maturation of the circadian rhythm of the adrenocortical functions in human neonates and infants. Hormone Research, 12, 237-244. doi:10.1159/000179126

[17] Metzger, D.L., Wright, N.M., Veldhuis, J.D., Rogol, A.D. and Kerrigan, J.R. (1993) Characterization of pulsatile secretion and clearance of plasma cortisol in premature and term neonates using deconvolution analysis. The Journal of Clinical Endocrinology \& Metabolism, 77, 458-463. doi:10.1210/jc.77.2.458

[18] Aucott, S.W., Watterberg, K.L., Shaffer, M.L. and Donohue, P.K. (2008) Do cortisol concentrations predict short-term outcomes in extremely low birth weight infants? Pediatrics, 122, 775-781. doi: $10.1542 /$ peds. $2007-2252$ 


\section{ABBREVIATIONS}

17-OHP: 17-hydroxyprogesterone;

ACTH: adrenocorticotrophic hormone;

CAH: congenital adrenal hyperplasia;

CPAP: continuous positive airway pressure;

FESH: first episode of systemic hypotension;
hCRH: human corticotrophin-releasing hormone; ICU: intensive care unit; IQR: interquartile range; HFO: high frequency oscillation; PMA: postmenstrual age. 